Discussion Paper No. 16-013

\title{
Fiscal Competition and Public Debt
}

Eckhard Janeba and Maximilian Todtenhaupt

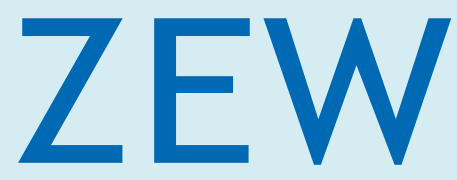

Zentrum für Europäische Wirtschaftsforschung $\mathrm{GmbH}$

Centre for European Economic Research 
Discussion Paper No. 16-013

\title{
Fiscal Competition and Public Debt
}

\author{
Eckhard Janeba and Maximilian Todtenhaupt
}

Download this ZEW Discussion Paper from our ftp server:

http://ftp.zew.de/pub/zew-docs/dp/dp16013.pdf

Die Discussion Papers dienen einer möglichst schnellen Verbreitung von neueren Forschungsarbeiten des ZEW. Die Beiträge liegen in alleiniger Verantwortung der Autoren und stellen nicht notwendigerweise die Meinung des ZEW dar.

Discussion Papers are intended to make results of ZEW research promptly available to other economists in order to encourage discussion and suggestions for revisions. The authors are solely responsible for the contents which do not necessarily represent the opinion of the ZEW. 


\title{
Fiscal Competition and Public Debt*
}

\author{
Eckhard Janeba ${ }^{\dagger}$ \\ University of Mannheim, CESifo and ZEW
}

Maximilian Todtenhaupt $t^{\ddagger}$

University of Mannheim and ZEW

February 9, 2016

\begin{abstract}
The existing theoretical literature on fiscal competition has to a large extent ignored the role of government debt as a determinant of taxes and productive public spending. We develop a simple model of fiscal competition with government borrowing. If a default on government debt is no option, initial debt levels play no role in fiscal competition. This neutrality result is overturned when a default is possible. A government that is constrained in its borrowing due to a possible default responds optimally by lowering spending on durable public infrastructure, which in turn induces more aggressive tax setting. A rise in exogenous firm mobility reinforces the link between legacy debt and fiscal competition. Our model may help explain the observation that highly indebted countries in Europe have decreased corporate tax rates over-proportionally. Our model may also be useful for evaluating decentralization reforms in which the power to tax firms is devolved to lower levels of governments which differ in their initial debt levels.
\end{abstract}

JEL Classification: H25, H63, H73, H87

Keywords: Asymmetric Tax Competition, Business Tax, Sovereign Debt, Inter-Jurisdictional Tax Competition

\footnotetext{
*We thank Sander Renes, Kai A. Konrad, Marko Köthenbürger, Marco Runkel and the participants of the Norwegian-German Seminar in Public Economics, Munich, and the Workshop on Political Economy, Dresden, for their helpful comments on a previous draft of the paper. The usual disclaimer applies. Eckhard Janeba gratefully acknowledges the support from the Collaborative Research Center (SFB) 884 "Political Economy of Reforms", funded by the German Research Foundation (DFG).

†University of Mannheim, Department of Economics, L7 3-5, D-68131 Mannheim, Germany, janeba@unimannheim.de

$\ddagger$ Centre for European Economic Research (ZEW), Department of Corporate Taxation and Public Finance, L7 1, D-68131 Mannheim, Germany, todtenhaupt@zew.de.
} 


\section{Introduction}

The recent financial crisis caused substantial increases in government debt levels, raising concerns about the sustainability of government finances. Governments may need to increase taxes or cut spending to fix this in the short run. Meanwhile governments at various levels use lower business taxes and improvements in infrastructure to lure economic activity and thus raise employment and welfare. These two observations lead to important questions concerning the interaction between fiscal competition and government debt.

First, does government debt influence fiscal competition among jurisdictions? So far the theoretical literature on tax competition has mostly ignored public debt levels as a factor in inter-jurisdictional competition for business investment. One possible reason is that in the absence of a government default there is no obvious reason why governments cannot separately optimize public borrowing and fiscal incentives for private investment, thus precluding any interaction between the initial debt level and business taxes. However, in the light of public defaults in both developing and developed jurisdictions and a surge in policy measures designed to limit budget deficits and government debt through fiscal rules, unconstrained public borrowing is an unrealistic assumption for some jurisdictions. ${ }^{1}$ In this paper we argue that initial debt levels do indeed play a role in fiscal competition in case one relaxes the assumption of unrestricted borrowing.

This leads to our second question: assuming that there are constraints on government borrowing because a default may happen, does initial (legacy) government debt then lead to more or less aggressive fiscal competition? Cai \& Treisman (2005) argue that asymmetries in certain jurisdictional characteristics may have a substantial effect on how these jurisdictions behave in fiscal competition and how they react to an increase in tax base mobility. In this regard, initial debt levels may constitute an important but so far largely neglected factor. Highly indebted jurisdictions have less fiscal space for spending on goods like public infrastructure that make the location more attractive. Jurisdictions may compensate for this by setting their taxes more aggressively. However, competing against jurisdictions that generally have lower debt levels and thus better infrastructure may require very low tax rates of highly indebted jurisdictions which in turn aggravates the fiscal situation. ${ }^{2}$

The main contribution of this paper is to formally model and to specify the suggested link between initial government debt and subsequent fiscal competition, taking the possibility of a government default into account. Moreover, as technological progress and the globalization of business make firm location choices more flexible, we analyze how an increase in capital mobility (by loosening firm attachment to a specific jurisdiction) affects the interaction

\footnotetext{
${ }^{1}$ By "unconstrained" we mean that the government can borrow as much as it wants at the current interest rate assuming no default.

${ }^{2}$ Cursory evidence points to the relevance of this channel. While most governments decreased corporate tax rates from 2002 to 2012, the cuts tend to be more substantial in countries with high levels of public debt at the beginning of the period. For example Greece and Cyprus, both highly indebted countries in 2002, had decreased their corporate tax rates by more than 40 percent by 2012. According to the World Bank's World Development Indicators, the debt-to-GDP ratios on the central government level in 2002 were 123 and 159 percent for Greece and Cyprus, respectively.
} 
between government debt and fiscal competition. Greater capital mobility drives down tax rates on firms, a direct effect that is well known in the literature. Furthermore, we show that globalization, in terms of higher firm mobility, tends to reinforce the impact of initial debt on fiscal competition, which we identify as a novel indirect effect.

Our model also allows us to link the causes of initial public debt levels to its comparative static effects. In particular, if higher legacy debt is the result of higher government consumption expenditure in the past - and thus less initial public infrastructure - the effects of legacy debt on fiscal competition are reinforced. Jurisdictions with high initial public debt and low public infrastructure become even more aggressive in subsequent tax competition. By contrast, if higher legacy debt is due to spending on initial public infrastructure the negative effect of legacy debt is mitigated and possibly overturned.

In our analysis we use a simple inter-temporal setting to investigate the interaction between fiscal competition and government debt. In our two-period and two-jurisdictions model governments compete for private investment projects by setting tax rates and investing in public infrastructure. The latter raises the attractiveness of the location for firms in the following period. In addition, governments can issue debt in the international credit market. We contribute to the literature on fiscal competition by considering jointly endogenous levels of government debt, productive public infrastructure spending and taxes on firms. To the best of our knowledge, we are the first to relax the assumption of unrestricted public borrowing in the context of fiscal competition, thereby linking initial debt levels and government choices in the fiscal competition game.

To highlight the role of a government default in fiscal competition, we first derive a neutrality result for a situation in which both governments always repay all of the their existing debt (by assumption or because it is in the interest of the government to repay the debt when the cost of default is very high). We assume a linear intra-period utility function, thus, income effects from public debt are not at work ${ }^{3}$. In this situation no change in a jurisdiction's exogenous initial debt level does affect fiscal competition, that is, public investment in infrastructure and tax rates in subsequent periods are unaffected. There is no change in the location decision of any firm. Of course, higher initial debt levels affect borrowing and public consumption good levels in the jurisdiction experiencing the debt increase and thus are not neutral overall. The logic behind the neutrality result is that, as long as default is no option, unconstrained public borrowing leads to equalization of marginal utilities across periods. The choice of public infrastructure investment then boils down to a comparison of forgone (public good) consumption in the first period versus increased consumption in the second period because the jurisdiction becomes a more attractive firm location due to better infrastructure. We also show that higher capital mobility (i.e. less

\footnotetext{
${ }^{3}$ Jensen \& Toma (1991), by contrast, assume a quasi-linear (within period) utility function and therefore derive different results without considering a default. In their model, an increase in a jurisdiction's debt implies more interest payments subsequently, which lowers public good provision and tends to raise the jurisdiction's tax rate. The effect on equilibrium tax rates depends on the nature of the strategic interaction in tax rates (strategic complementarity or substitutes).
} 
attachment of firms to a specific jurisdiction) generally decreases equilibrium tax rates, which is standard in the literature.

We then allow for a government default. The possibility of default limits how much foreign creditors are willing to lend. We ask whether and how changes in the (exogenous) initial debt level of a jurisdiction affect subsequent borrowing and fiscal competition. Here, the marginal utilities of consumption are not equalized across periods through government borrowing and hence the cost of public infrastructure depends on the initial debt. A high level of legacy debt increases the marginal cost of spending on public infrastructure. Governments optimally respond to a higher initial debt burden by reducing public investment. This in turn triggers a further adjustment: to compensate for the resulting disadvantage in the fiscal competition game due to worse public infrastructure the government imposes a lower tax on firms, while taxes in the other jurisdiction may rise, thus leading to tax divergence. In other words, governments with good public infrastructure can afford to impose higher tax rates ceteris paribus, and vice versa. We show that a rise in capital mobility reinforces the mechanism. Less attachment of firms to a specific location makes the negative effect of higher legacy debt on public investment and taxes stronger because it decreases the government's ability to tax firms and makes it more responsive to burdens from existing debt repayments.

There is a large body of research on inter-jurisdictional competition in taxes (see Keen \& Konrad, 2013) and public infrastructure investment (e.g. Noiset, 1995; Bucovetsky, 2005), as well as, on the interaction between these two policy instruments (e.g. Wilson, 2005; Petchey \& Shapiro, 2009; Hauptmeier et al., 2012; Matsumoto, 1998). It is also common both to separately analyze the evolution of government debt (e.g. Barro, 1979; Acharya \& Rajan, 2013) and to incorporate it into comprehensive fiscal policy models (e.g. Battaglini \& Coate, 2008). However, while empirical findings suggest some interaction (e.g. Winner, 2005) there is hardly any theoretical work that looks at the interplay between fiscal competition and public debt.

There are two exceptions. Arcalean (2015) analyzes the effects of financial liberalization on capital and labor taxes as well as budget deficits in a multi-country world where countries are linked through capital mobility. Financial liberalization works similar to an increase in firm mobility in our setup. In contrast to our analysis, he focuses on endogenous budget deficits that change due to financial liberalization because permanently lower tax rates on capital due to more intensive tax competition lead to higher capital accumulation in the future. This in turn makes it attractive for the median worker to bring forward the higher benefits of capital taxation through government debt. The mechanism works at the early stages of financial liberalization when capital taxes are relatively high, but not when they are already low due to advanced liberalization.

The other exception is the contribution by Jensen \& Toma (1991) who develop a twoperiod, two-jurisdiction model. They assume that in the first period each government chooses the optimal level of debt taking into account any negative effects of repayment demands in 
the tax competition game. When governments have to balance the budget in the second period, a higher level of first-period debt leads to a higher level of taxation and a lower level of public good provision in that jurisdiction. In the other jurisdictions, either a higher or a lower tax rate is set depending on whether tax rates are strategic complements or substitutes. ${ }^{4}$ The present paper differs from this setting in three important aspects: First, we allow for a default on government debt which endogenously limits the maximum level of public debt. Second, we introduce public infrastructure investment as an additional fiscal instrument that interacts with the setting of taxes. Finally, we assume a linear within-period utility function, which allows us to abstract from the intra-period transmission mechanism identified by Jensen \& Toma (1991). Our approach is more tractable in an otherwise more complex model and highlights the novel inter-temporal mechanism through which legacy debt operates.

The paper is structured as follows. In Section 2 we describe the model framework. We then proceed to the equilibrium analysis in Section 3 which also contains the main results. Section 4 provides the conclusion.

\section{The Model}

We start with a brief overview of the model. The world consists of two jurisdictions, $i=1,2$, linked through the mobility of a tax base. The tax base is the outcome of the location decisions of a continuum of firms and generates private benefits such as employment and income. In addition, revenues from taxing the base are used by the government for spending on a public consumption good, a public infrastructure good, and debt repayment. Better infrastructure makes a jurisdiction more attractive, while taxes work in the opposite direction. The economy lasts for two periods $t=1,2$. Both jurisdictions start with an initial (legacy) debt level $b_{i 0}$ and issue new debt in the first period in an international credit market at a given interest rate. We pay particular attention to a government's willingness to repay its debt in period 2, which endogenously limits the maximum available credit.

The government is assumed to be benevolent in the sense that each government maximizes a linear combination of the number of firms in its jurisdiction and the level of the public consumption good, in line with many models of fiscal competition. There are two inter-temporal decisions for a government to be made in period 1: the level of borrowing and the spending on public infrastructure. The latter is a long term decision in the sense that public investment is costly in period 1 , but carries benefits only in period 2. This assumption captures the durable good nature of infrastructure projects. We consider a fiscal policy game between the two governments without commitment, that is, governments choose fiscal policy in each period non-cooperatively and there is no commitment in period 1 for fiscal policies in period 2 .

\footnotetext{
${ }^{4} \mathrm{An}$ interesting empirical application for this model in the case of interactions in borrowing decisions can be found in Borck et al. (2015).
} 
Fiscal competition has two dimensions: tax rate competition in periods 1 and 2, where governments set a uniform tax on each firm in their location, and competition in infrastructure spending which determines the attractiveness of a location for private investment in period 2 only. We characterize the equilibrium of this game and investigate comparative statics with respect to the level of legacy debt and the extent of firm mobility. The former features prominently due to the recent financial and economic crisis. The latter mirrors the increasing extent of footloose capital .

\section{$2.1 \quad$ Firms}

We begin the description of the model with the location of the tax base, which follows a simple Hotelling (1929) approach. ${ }^{5}$ In each period there is a continuum of firms that choose a jurisdiction to locate in. Firms are heterogeneous in terms of their exogenous bias towards one of the two jurisdictions, which is captured by the firm-specific parameter $\alpha \in[0,1]$. Firms can switch their investment location between periods at no cost. For the time being we, therefore, describe a generic decision problem of a firm without time reference. A firm of type $\alpha$ receives a net benefit $\varphi_{i}$ in jurisdiction $i=1,2$ given by

$$
\begin{gathered}
\varphi_{1}=\psi+\alpha \nu+\rho q_{1}-\tau_{1}, \\
\varphi_{2}=\psi+(1-\alpha) \nu+\rho q_{2}-\tau_{2},
\end{gathered}
$$

respectively. The terms $\psi+\alpha \nu$ and $\psi+(1-\alpha) \nu$ represent the exogenous returns received. The general return $\psi$ is assumed to be sufficiently positive so that overall returns $\varphi_{i}$ are non-negative. Therefore, the firm always prefers locating in one of the two jurisdictions rather than not carrying out an investment at all. The second component of the private return is the firm-specific return in each jurisdiction weighted by $\nu>0$. The parameter $\nu$ allows us to capture the strength of the exogenous component relative to the policy induced component. Variation in $\nu$ changes the degree of fiscal competition, which we analyze below in more detail. The overall return to investment in a jurisdiction $i$ further increases when the jurisdiction has a stock of public infrastructure in place at level $q_{i} \geq 0$. The effectiveness of public infrastructure is captured by the parameter $\rho \geq 0$ and is not firm-specific. ${ }^{6}$ Finally, the uniform tax $\tau_{i}$ reduces the return. We assume that the tax is not firm-specific, perhaps because the government cannot determine a firm's type and for administrative reasons cannot choose a more sophisticated tax function. ${ }^{7}$

The marginal firm is indifferent between the two locations for the given policy parameters.

\footnotetext{
${ }^{5}$ Our model shares some features with classical models of tax competition as, for example, Zodrow \& Mieszkowski (1986) and Wilson (1986). Our approach is analytically simpler to handle which is crucial in the in the presence of many government instruments including public infrastructure and government debt.

${ }^{6}$ In principle, we could interact the firm-specific component and the effectiveness of public infrastructure. This would lead to a less tractable framework, however.

${ }^{7}$ We model the location decision of investment rather than the size of particular investment projects such that the uniform, average tax is the relevant measure for a firm's decision making.
} 
A firm of type $\alpha$ invests in jurisdiction 1 if $\varphi_{1} \geq \varphi_{2}$, which defines a threshold

$$
\tilde{\alpha}=\frac{1}{2}+\frac{\tau_{1}-\tau_{2}+\rho\left(q_{2}-q_{1}\right)}{2 \nu},
$$

such that a firm invests in jurisdiction 1 whenever $\alpha \geq \tilde{\alpha}$. Note that the value of the marginal firm's type is a linear function of the tax and public infrastructure differentials, which is a convenient property. In addition, the sensitivity of the threshold with respect to both tax rates and infrastructure spending depends on the parameter $\nu$. Higher values of $\nu$ represent less sensitivity.

Let $\alpha \in[0,1]$ be uniformly distributed on the unit interval. Under the assumption that the marginal firm is interior, that is $\tilde{\alpha} \in(0,1)^{8}$, the number of firms in each jurisdiction is given by $N_{1}=1-\tilde{\alpha}$ and $N_{2}=\tilde{\alpha}$ or, more generally,

$$
N_{i}\left(\tau_{i}, \tau_{j}, q_{i}, q_{j}\right)=\frac{1}{2}+\frac{\rho \triangle q_{i}-\Delta \tau_{i}}{2 \nu}
$$

where $\Delta q_{i}=q_{i}-q_{j}$ and $\Delta \tau_{i}=\tau_{i}-\tau_{j}$. Firms split evenly between the two jurisdictions when both policies are symmetric across jurisdictions.

\subsection{Governments}

The government in each jurisdiction takes several decisions in each period. In both periods, it sets a uniform tax $\tau_{i t}$ and provides a public consumption good $g_{i t}$, which can be produced by transforming one unit of the private good into one unit of the public consumption good. In the first period, the government also decides on public infrastructure investment $m_{i t}$, and the level of newly issued debt $b_{i 1}$. If the government honors the debt contract, $b_{i 1}$ is repaid in period 2 .

Public investment raises the existing stock of public infrastructure $q_{i t}$. In each period a share $\delta \in[0,1]$ of $q_{i t}$ depreciates such that the law of motion for $q_{i t}$ is denoted by

$$
q_{i t}=(1-\delta) q_{i t-1}+m_{i t-1} .
$$

In our two-period model, jurisdictions are endowed with an exogenous level of public infrastructure $q_{i 0}=\bar{q}_{i}$ in period 1 . Of course, a jurisdiction's level of public infrastructure may be linked to the existing level of government debt in that jurisdiction. We show below how such a link affects our result. The cost for public infrastructure investment is denoted by $c$, which is an increasing function of $m_{i}$ and strictly convex with $c^{\prime}\left(m_{i}\right)>0, c^{\prime \prime}\left(m_{i}\right)>0 .{ }^{9}$

Using $g_{i t}$ and $b_{i t}$ to denote the quantity of the public consumption good provided and the

\footnotetext{
${ }^{8}$ Similar to Hindriks et al. (2008) we make this assumption to avoid the less interesting case of a concentration of all investment in one of the two jurisdictions which would be the case if $\tilde{\alpha}$ was outside the unit interval.

${ }^{9}$ To simplify notation, we have suppressed the time subscript in $m_{i}$ since it is effectively only chosen in period 1 .
} 
debt level, respectively, in jurisdiction $i$ in period $t$, the period-specific budget constraints for the government in $i=1,2$ can be stated as follows:

$$
\begin{aligned}
& g_{i 1}=\tau_{i 1} N_{i 1}-c-(1+r) b_{i 0}+b_{i 1} \\
& g_{i 2}=\tau_{i 2} N_{i 2}-(1+r) b_{i 1} .
\end{aligned}
$$

Government borrowing takes place in the international credit market at a constant interest rate $r$. The budget constraints shown above assume for the time being that government debt is repaid and therefore no default is considered. In our subsequent analysis we pay attention to the possibility of default. ${ }^{10}$

Each government is assumed to maximize the discounted benefit arising from attracting firms and government spending on a public consumption good according to the following specification:

$$
U^{i}=h_{1}\left(u_{i 1}\right)+\beta h_{2}\left(u_{i 2}\right)=h_{1}\left(N_{i 1}+\gamma g_{i 1}\right)+\beta h_{2}\left(N_{i 2}+\gamma g_{i 2}\right) .
$$

We think of (6) as the utility function of a representative citizen who benefits from attracting firms or capital because it generates income and employment. Here, we simply use the number of firms in jurisdiction $i, N_{i}$, as an indicator of this benefit. In addition, attracting firms increases the tax base and generates higher tax revenues. The marginal benefit of the public good, $\gamma>1$, implicitly determines the relative weight attached to the private benefit and public consumption. The linear structure of the within-period utility function is in line with earlier literature (e.g. Brueckner, 1998) in order to solve for Nash tax rates explicitly. This assumption differs from Jensen \& Toma (1991) who assume a strictly concave function for the benefit of the public good (within the function $h_{2}$ ). As mentioned earlier this is done for tractability reasons and for showing the novel mechanism at work in our model. $\beta$ is the discount factor which we assume to equal $\frac{1}{1+r}$.

The inter-temporal structure of the utility function assumes that the functions $h_{1}$ and $h_{2}$ are concave, and at least one of them is strictly concave. We assume this for $h_{1}$, such that $h_{1}^{\prime}>0, h_{2}^{\prime}>0, h_{1}^{\prime \prime}<0, h_{2}^{\prime \prime} \leq 0$. Below, we will consider two special cases in more detail: i) the functions $h_{1}$ and $h_{2}$ are identical and strictly concave (e.g. logarithmic), and ii) $h_{1}$ is logarithmic and $h_{2}$ is linear, making the inter-temporal utility function quasi-linear.

So far, we have implicitly assumed that public debt is repaid in both periods, such that creditors have no reason to restrict lending to the government. We now consider default on debt in period 2 through a willingness to pay constraint. A government honors the debt contract only when the net benefit of defaulting is smaller than the net benefit of paying back the debt. While the former is related to the size of the existing debt level, the latter involves a loss of access to the international credit market. In this model the world ends after period 2. Therefore, similar to Acharya \& Rajan (2013) we take a shortcut for modeling the

\footnotetext{
${ }^{10}$ We ignore the possibility of bailouts, which have been relevant in the financial crises in some cases, but go beyond the scope of this paper.
} 
loss of access to the credit market. We assume that a default in period 2 causes a utility loss of size $z$ in this period, representing the discounted value from being unable to borrow in the future. We denote the government's default decision with the binary variable $\kappa_{i}=\{0,1\}$, where 0 stands for no default and 1 for default. Then the period 2 utility in jurisdiction $i$ is given by

$$
u_{i 2}=N_{i 2}+\gamma\left(\tau_{i 2} N_{i 2}-\left(1-\kappa_{i}\right)(1+r) b_{i 1}\right)-\kappa_{i} z
$$

We do not model the default decision on government debt regarding initial (legacy) debt $b_{i 0}$ in period 1 . This could be done in principle and would require an endogenous lending decision in period 0 but is not within the scope of our paper. Our focus is rather on the role of exogenous legacy debt levels on fiscal competition. Legacy debt levels may accumulate due to unforeseen shocks as in the European financial and economic crisis, or may play a role when switching to a more decentralized federal system which also includes tax setting at the jurisdictional level (as is considered in the reform debate on fiscal federalism in Germany). Our assumption of repayment of legacy debt is reasonable if its size is small enough so that default in period 1 is not attractive. Even if a government default was attractive in period 1 , it would not occur in equilibrium since creditors would not have given any loans in the first place. ${ }^{11}$

\subsection{Equilibrium}

The equilibrium definition has two components. The economic equilibrium is straightforward as this refers only to the location decision of firms. There is no linkage across periods because relocation costs for firms are zero. An economic equilibrium in period $t=1,2$ is a location for each firm for given levels of taxes and infrastructure in that period so that the net return to investment is maximized. The economic equilibrium is fully characterized in Section 2.1.

The second component comprises the policy game between governments. We assume the following timing of events. In period 1 , governments decide simultaneously on how much to invest (i.e. set $m_{i}$ ), set new debt $b_{i 1}$, and choose the tax rate $\tau_{i 1}$, as well as, the public good $g_{i 1}$, assuming that it pays back the legacy debt $b_{i 0}$. Then firms decide where to invest. In period 2, governments simultaneously choose tax rate $\tau_{i 2}$, public good $g_{i 2}$, and decide on the default of existing debt $b_{i 1}$. Subsequently, firms again make their location choices.

At all times we assume that governments observe all previous decisions. The timing of moves implies that there is no commitment in the sense that period 2 variables cannot be committed to in period 1 . We consider a sub-game perfect Nash equilibrium and solve the model by backward induction.

\footnotetext{
${ }^{11}$ For completeness we have checked that there exists a set of sufficiently small initial debt levels that does not lead to a default but still influences the subsequent choice of fiscal instruments.
} 


\section{Results}

\section{$3.1 \quad$ Period 2}

We begin with analyzing the government decision making in period 2. At that stage, a government decides on its tax rate, public consumption good level and default, taking as given the policy choices of period 1, that is, the debt levels $b_{i 1}$ and the public infrastructure $m_{i}$ in both jurisdictions $i=1,2$. A period 2 Nash equilibrium is a vector of tax rates, public good levels and default decisions such that each government maximizes its period 2 sub-utility taking the other government's fiscal policy decisions in that period as given.

We consider the maximization problem of government $i$ in period 2 and insert the budget constraint for period 2 into the sub-utility function. We implicitly assume that the level of public good provision is strictly positive and verify later that this is indeed the case. Government $i$ maximizes period 2 utility as given by equation (6) by choosing its tax rate, where $N_{i 2}$ is given by (2) adding appropriate time subscripts. The first order condition is given by

$$
U_{\tau_{i 2}}^{i}:=\frac{\partial U^{i}}{\partial \tau_{i 2}}=h_{2}^{\prime} \frac{\partial\left(N_{i 2}\left(1+\gamma \tau_{i 2}\right)\right)}{\partial \tau_{i 2}}=0 .
$$

For the within period 2 decision the outer utility function $h_{2}$ can be ignored (as long as $h_{2}^{\prime}>0$, which we assume). Solving the system of two equations with two unknowns given by condition (7) we obtain $\tau_{i 2}=\nu+\frac{\rho \Delta q_{i 2}}{3}-\frac{1}{\gamma} \cdot{ }^{12}$ Note that $\Delta q_{i 2}=\Delta q_{i 2}\left(m_{i}, m_{j}\right)=$ $\triangle \bar{q}_{i}(1-\delta)+\triangle m_{i}$ is a linear function of the inter-jurisdictional differences in existing public infrastructure $\triangle \bar{q}_{i}=\bar{q}_{i}-\bar{q}_{j}$ and additional investment in public infrastructure $\triangle m_{i}=$ $m_{i}-m_{j}$. Inserting these candidate tax rates into (2) we find the marginal firm to be of type $\tilde{\alpha}=\frac{1}{2}-\frac{\rho \Delta q_{i 2}}{6 \nu}$, from which we can derive the number of firms $N_{i 2}=\frac{1}{2}+\frac{\rho \Delta q_{i 2}}{6 \nu}$.

We now analyze the default decision in period 2. For this purpose we need to compare the utilities under default and under no default. A government's fiscal decisions other than debt repayment (tax and public good) could depend on the default decision. However, if we let the cost and benefit of default enter additively, the linear structure of the within period utility function cuts this link as long as the public consumption good is non-negative regardless of the default decision. The comparison of the two utility levels for given fiscal policy decisions in both jurisdictions defines a willingness-to-pay threshold $b^{w t p}$ at which the government is indifferent:

$$
\begin{aligned}
u_{i 2}\left(\kappa_{i}=1\right)=u_{i 2}\left(\kappa_{i}=0\right) & \Leftrightarrow N_{i 2}+\gamma N_{i 2} \tau_{i 2}-z=N_{i 2}+\gamma\left(N_{i 2} \tau_{i 2}-b^{w t p}(1+r)\right) \\
& \Leftrightarrow b^{w t p}=\frac{z}{\gamma(1+r)} .
\end{aligned}
$$

If $b_{i 1}>b^{w t p}$, a jurisdiction does not repay its debt as the benefits from default outweigh

\footnotetext{
${ }^{12}$ The second order condition is fulfilled because $N_{i 2}$ is a linear function of tax rates and depends negatively on the own tax rate.
} 
the related costs, and vice versa. An interesting point to note is that the default decision in jurisdiction $i$ does not depend on the default decision in jurisdiction $j$, as long as the condition $g_{i} \geq 0$ is not binding. Furthermore, $b^{w t p}$ is identical across jurisdictions because they face the same $z$. Heterogeneous utility losses of default would imply heterogeneous willingness-to-pay thresholds, an asymmetry which we address further below.

So far we assumed that the level of the public consumption good is non-negative and maximized period 2 sub-utility with respect to the tax rate. We now review when this is indeed a legitimate approach. Assuming an interior solution for $g_{i 2}$, tax revenues in jurisdiction $i$ in period 2 are given by $\tau_{i 2} N_{i 2}$, which we derived above. In case of no default we need to subtract the amount $(1+r) b_{i 1}$ from tax revenues to obtain $g_{i 2}$. Bearing in mind the maximum $b_{i 1}$ consistent with no default, we obtain the constraint $\frac{z}{\gamma}>\tau_{i 2}^{*} N_{i 2}^{*}$. As the right hand side is not a function of the loss of default, a sufficiently large value of $z$ ensures that this condition is met, an assumption that we make in the following. We summarize our results in the following Proposition.

Proposition 1. Let $2>\gamma \nu>1$. For given public infrastructure investment levels $\left(m_{1}, m_{2}\right)$ and borrowing in period $1\left(b_{i 1}\right)$, there exists a unique Nash equilibrium for the period 2 fiscal policy game with

$$
\begin{aligned}
\tau_{i 2}^{*}\left(m_{i}, m_{j}\right) & =\nu+\frac{\rho \Delta q_{i 2}}{3}-\frac{1}{\gamma}, \\
\kappa_{i}^{*}\left(b_{i 1}\right) & = \begin{cases}0 & \text { if } b_{i 1} \leq b^{w t p} \\
1 & \text { if } b_{i 1}>b^{w t p}\end{cases} \\
g_{i 2}^{*}\left(m_{i}, m_{j}, b_{i 1}\right) & =\tau_{i 2}^{*} N_{i 2}^{*}-\left(1-\kappa^{*}\right)(1+r) b_{i 1},
\end{aligned}
$$

and the number of firms in $i$ given by $N_{i 2}^{*}\left(m_{i}, m_{j}\right)=N_{i 2}=\frac{1}{2}+\frac{\rho \Delta q_{i 2}}{6 \nu}$ where $\Delta q_{i 2}=$ $\triangle \bar{q}_{i}(1-\delta)+\triangle m_{i}$.

Proposition 1 has several interesting implications. First, the equilibrium tax rate of jurisdiction $i$ increases with the value of the gross location benefit $\nu$, the own investment in infrastructure $m_{i}$ and the marginal benefit of the public good $\gamma$, while the tax rate decreases in infrastructure spending by the other government $m_{j}$. Better infrastructure provides more benefits to firms that are partially taxed. The tax rate is positive if $\nu$ is sufficiently large. Moreover, divergence in tax rates stems solely from differences in public infrastructure, $\triangle q_{i 2}$. Second, the average tax rate across jurisdictions $\bar{\tau}_{2}=\frac{\tau_{12}^{*}+\tau_{22}^{*}}{2}=\nu-\frac{1}{\gamma}$ is independent of $\left(m_{i}, m_{j}\right)$, as the terms involving public infrastructure offset each other, but decreases when the general location benefit $\nu$ declines, making firms more sensitive to policy differences. 


\subsection{Period 1}

When analyzing the Nash equilibrium in period 1, we first put our focus on asymmetries in initial public debt levels and derive the main results. We thus abstract from any additional, potentially confounding asymmetries and assume that jurisdictions only differ in $b_{i 0}$ and are identical otherwise. In particular, we let initial levels of public infrastructure be symmetric $\left(\bar{q}_{i}=\bar{q}_{j}\right)$. In a second step, we relax this assumption allowing for an asymmetric stock of public infrastructure in period 1 as well as for a link between $b_{i 0}$ and $q_{i 0}$.

Beginning with the second stage of period 1 we note that firms choose their location similarly to period 2 because a firm's location decision is reversible between periods at no cost. In the first stage of period 1 where fiscal policy is determined, the governments face a potential constraint pertaining to additional borrowing. ${ }^{13}$ Proposition 1 shows that a government defaults when its debt level exceeds $b^{w t p}$. Therefore, no lender will give loans above this threshold. We thus have an upper limit on borrowing in the form of a willingnessto-pay condition which is defined as follows.

Condition 1 (Willingness-to-pay Condition). $b_{i 1} \leq b^{w t p}=\frac{z}{\gamma(1+r)}$.

The advantage of Condition 1 is its simplicity as it does not depend on earlier public investment decisions or the level of existing debt. The government budget constraint for period 2 is therefore as in equation (4).

Let us denote by $b_{i 1}^{\text {des }}$ the desired level of borrowing in period 1 if the default problem in period 2 is ignored. If utility is strictly concave in $b_{i 1}$, and assuming an interior level of the public consumption good, the optimal period 1 debt is given by

$$
b_{i 1}^{*}=\min \left\{b_{i 1}^{\text {des }}, b^{w t p}\right\}
$$

If Condition 1 is not binding, that is $b_{i 1}^{\text {des }}<b^{w t p}$, the government chooses its desired borrowing level. On the other hand, if Condition 1 is binding, governments choose $b_{i 1}^{*}=b^{w t p}$ because, if utility is strictly concave in $b_{i 1}$, relaxing this constraint improves welfare ceteris paribus.

We now consider two separate cases. First, we assume that the willingness-to-pay condition is not binding in either of the jurisdictions. The assumption is correct if, for example, the cost of punishment $(z)$ in the form of a loss of access to credit and thus $b^{w t p}$ is very large, so that $b_{i 1}^{*}=b_{i 1}^{\text {des }}<b^{w t p}$. In this case we can derive and use the first order conditions for all fiscal variables in period 1 , taking into account the variables' impact on period 2 equilibrium values. In a second step, we turn to the case where in at least one of the two jurisdictions Condition 1 is binding, perhaps even in both, that is $b_{i 1}^{*}=b^{w t p}$. A government's set of first order conditions is reduced by one if the jurisdiction is constrained in its borrowing (or more precisely, the first order condition for $b_{i 1}$ does not hold with equality). We show that the implications from changes in legacy debt depend on whether Condition 1 is binding or not.

\footnotetext{
${ }^{13}$ As explained earlier we assume that default on debt from period 0 is not an issue because legacy debt is sufficiently small.
} 


\section{Case I: Willingness-to-pay Condition is not binding in both jurisdictions}

After inserting budget constraints, government $i$ solves the following maximization problem

$$
\begin{gathered}
\max _{\tau_{i 1}, m_{i}, b_{i 1}} U^{i}=h_{1}\left(N_{i 1}+\gamma\left(\tau_{i 1} N_{i 1}-c-(1+r) b_{i 0}+b_{i 1}\right)\right) \\
+\beta h_{2}\left(N_{i 2}^{*}+\gamma\left(\tau_{i 2}^{*} N_{i 2}^{*}-(1+r) b_{i 1}\right)\right)
\end{gathered}
$$

subject to $g_{i 1} \geq 0$ and $m_{i} \geq 0$. The values for period $2\left(\tau_{i 2}^{*}, \kappa^{*}, N_{i 2}^{*}\right)$ are given in Proposition 1 and are correctly anticipated. Condition 1 ensures that debt contracts are always honored, as shown in expression (8). We again must make sure that the level of public good consumption in period $1, g_{i 1}$, is non-negative, which we check later. The first order conditions for $i=1,2$ are

$$
\begin{aligned}
U_{\tau_{i 1}}^{i} & :=\frac{\partial U^{i}}{\partial \tau_{i 1}}=h_{1}^{\prime} \frac{\partial\left(N_{i 1}\left(1+\gamma \tau_{i 1}\right)\right)}{\partial \tau_{i 1}}=0, \\
U_{m_{i}}^{i} & :=\frac{\partial U^{i}}{\partial m_{i 1}}=-h_{1}^{\prime} \gamma c^{\prime}+\beta h_{2}^{\prime} \frac{\partial\left(N_{i 2}\left(1+\gamma \tau_{i 2}\right)\right)}{\partial m_{i}}=0, \\
U_{b_{i 1}}^{i} & :=\frac{\partial U^{i}}{\partial b_{i 1}}=\gamma h_{1}^{\prime}-\beta \gamma(1+r) h_{2}^{\prime}=h_{1}^{\prime}-h_{2}^{\prime}=0,
\end{aligned}
$$

where $h_{1}^{\prime}$ and $h_{2}^{\prime}$ are the derivatives of the functions $h_{1}$ and $h_{2}$. In first order condition (11) we made use of the assumption $\beta=\frac{1}{1+r}$. The second order conditions are fulfilled if the cost function for infrastructure investment is sufficiently convex and $h_{1}$ is sufficiently concave to make the allocation of resources in both periods optimal. We derive the full set of second order conditions in the Appendix. Note that $U^{i}$ is strictly concave in $b_{i 1}$, as long as at least one of the two functions $h_{1}$ or $h_{2}$ is strictly concave.

We solve the system of six first order conditions (three for each jurisdiction) as follows: Assuming that public consumption good levels are strictly positive, the first order conditions for tax rates (9) for both jurisdictions are independent of infrastructure investment as well as debt levels, and can be solved separately. We solve for the tax rates in a similar way as above in period 1 , yielding

$$
\tau_{i 1}^{*}=\nu-\frac{1}{\gamma}, N_{i 1}^{*}=\frac{1}{2} .
$$

Since by assumption the public infrastructure differential is zero in period 1 , the tax base is split in half between the two jurisdictions. As in period 2, the more footloose firms are (i.e. the lower $\nu$ ), the lower are equilibrium tax rates. This corresponds to the standard result that increasing capital mobility drives down equilibrium tax rates.

Using the first order condition for period 1 borrowing (11), $h_{1}^{\prime}=h_{2}^{\prime}$, we can simplify the condition for optimal infrastructure investment (10) to $\frac{\partial\left(\beta N_{i 2}^{*}\left(1+\gamma \tau_{i 2}^{*}\right)\right)}{\partial m_{i}}=\gamma c^{\prime}$. We use period 2 equilibrium values to obtain 


$$
c^{\prime}\left(m_{i}\right)=\frac{\beta \rho}{3}\left(1+\frac{\rho \triangle m_{i}}{3 \nu}\right) .
$$

A symmetric equilibrium $m_{i}=m_{j}=m^{*}$ always exists and in that case the condition is reduced to $c^{\prime}\left(m^{*}\right)=\frac{\beta \rho}{3}$. The symmetric equilibrium is unique if the cost function for public infrastructure $c$ is quadratic because the first order conditions are linear. Asymmetric equilibria may exist though. ${ }^{14}$ An interesting property of (13) is that it is independent of the initial debt level. Thus, the choice of $m_{i}$ is not affected by $b_{i 0}$.

The combined results from the first order conditions for taxes and infrastructure spending can now be used to determine the optimal borrowing level, as all other variables entering the arguments of $h_{1}$ and $h_{2}$ are determined via (10) and (11). For example, when the functions $h_{1}$ and $h_{2}$ are identical and the infrastructure spending as well as existing public infrastructure in period 1 are symmetric $\left(m_{i}=m_{j}, \bar{q}_{i}=\bar{q}_{j}\right)$, the first order condition implies $N_{i 1}=N_{i 2}$ and $g_{i 1}=g_{i 2}$, which in turn leads to $b_{i 1}^{\text {des }}=(1+r) b_{i 0}+\frac{c}{2+r}$. Interestingly, the desired level of borrowing in period 1 does not need to be the same across jurisdictions if initial debt levels differ. Still an equilibrium with symmetric infrastructure investment is maintained, as long as Condition 1 is not binding. Alternatively, when the inter-temporal utility function is quasi-linear (with $h_{1}(x)=\ln (x)$ and $h_{2}^{\prime \prime}=0$ ) the desired borrowing level is $b_{i 1}^{\text {des }}=\frac{1}{\gamma}-\frac{\nu}{2}+c+(1+r) b_{i 0}$, assuming again symmetric public infrastructure levels.

We finally need to check whether public consumption good levels are positive. This can be guaranteed by making appropriate assumptions on parameter values. For example, in the quasi-linear case, we obtain together with condition (11) that $g_{i 1}=\frac{1}{2 \gamma}>0$, so that the non-negativity constraint is always fulfilled. In the case of identical $h$ functions and symmetric infrastructure spending, $g_{i 1}=g_{i 2}=\frac{1}{2}\left(\nu-\frac{1}{\gamma}\right)-(1+r)\left((1+r) b_{i 0}+\frac{c}{2+r}\right)$, which is positive for sufficiently large levels of $\nu$ and small enough values for initial debt and cost of infrastructure. We summarize our findings in the following Proposition.

Proposition 2. Let $2>\gamma \nu>1$. Assume Condition 1 is not binding in both jurisdictions and initial public infrastructure levels are symmetric $\bar{q}_{i}=\bar{q}_{j}$.

a) A subgame perfect Nash equilibrium with symmetric infrastructure spending exists, in which tax is $\tau_{i 1}^{*}=\nu-\frac{1}{\gamma}$ and infrastructure spending and first period borrowing are implicitly given by $c^{\prime}\left(m^{*}\right)=\frac{\beta \rho}{3}$ and condition (11), respectively.

b) A change in a jurisdiction's legacy debt $\left(b_{i 0}\right)$ does not affect fiscal competition (tax rates and public infrastructure) and thus leaves firm location decisions in both periods unaffected. An increase in one jurisdiction's legacy debt affects its period 1 borrowing and its period 2 public consumption.

c) A decrease in $\nu$ (i.e. firms become more footloose) lowers tax rates in both periods.

\footnotetext{
${ }^{14}$ For example, a corner solution with one jurisdiction not investing at all exists if $c\left(m_{i}\right)=\frac{m_{i}^{2}}{2}$ and $2 \beta \rho^{2}>9 \nu>\beta \rho^{2}$. The first inequality ensures that one jurisdiction cannot benefit from infrastructure investment, while the second inequality makes sure that the jurisdiction finds a positive level of infrastructure $m_{i}^{*}=\frac{3 \beta \rho \nu}{9 \nu-\beta \rho^{2}}$ optimal.
} 
When governments can choose their desired borrowing level, the initial debt levels have no effect on fiscal competition in taxes and additional public infrastructure spending. The unconstrained decision on period 1 debt leads to equalization of marginal utilities across periods. The infrastructure spending decision then equalizes the benefits and costs from induced changes in public good consumption in periods 1 and 2. The result can be viewed as a neutrality theorem with respect to inter-temporal aspects of fiscal competition, ${ }^{15}$ which may explain why the existing literature has not much addressed the link between fiscal competition and public legacy debt. We show below that endogenous constraints on borrowing change our conclusion.

\section{Case IIa: Willingness-to-pay Condition is binding in both jurisdictions}

We now turn to the case where Condition 1 is binding in at least one of the two jurisdictions. In this situation a jurisdiction would like to run a higher debt level than lenders are willing to provide, as the latter correctly anticipate the default problem in period 2. Conceptually it is easier to start with the case in which Condition 1 is binding in both jurisdictions. Later we consider an asymmetric situation, in which only one jurisdiction is constrained.

The desired level of borrowing in period 1 is now higher than the willingness-to-pay threshold, $b_{i 1}^{\text {des }}>b^{w t p}$. In equilibrium, the first order condition for period 1 debt (11) does not hold with equality. Instead the optimal borrowing level equals the maximum feasible level given by $b^{w t p}$ due to the strict concavity of $U^{i}$ with respect to $b_{i 1}$. Condition (9) still holds and together for both jurisdictions the two conditions determine the Nash tax rates in period 1, which are identical to Case I: tax rates are the same and firms split evenly between the two jurisdictions. As before, we assume that the level of public consumption good is positive and thus an interior solution is obtained. In this case legacy debt does not affect period 1 taxes.

We are left with the two jurisdictions' first order conditions for public infrastructure investment (10). The absence of condition (11), however, now implies that the marginal utilities in periods 1 and 2 are not equalized, that is, one may have $h_{1}^{\prime} \neq h_{2}^{\prime}$. In particular, $h_{1}^{\prime}$ in (10) depends on the period 1 debt level and the level of infrastructure investment. This is the key difference to Case I.

Even with the solution for tax rates in period 1 from condition (9), we cannot solve explicitly for public investment levels, as the two conditions are nonlinear functions of $m_{i}$ and $m_{j}$. We examine comparative statics by totally differentiating the first order conditions for public infrastructure. This is a legitimate approach when we have an interior solution for the public consumption good and the tax rates for period 1 are determined in isolation from the other relevant first order conditions. The sign of the comparative static effects can be (partially) determined when we assume that the Nash equilibrium is stable, as suggested

\footnotetext{
${ }^{15}$ Note that we abstract from inefficiencies in the public good provision and thus ignore the intra-period transmission channel highlighted by Jensen \& Toma (1991) to focus on the inter-temporal effect of initial public debt.
} 
by Dixit (1986). In this case the sign of the own second order derivative regarding infrastructure spending is negative, $U_{m_{i}}^{i^{\prime}}<0$, and importantly, the direct effects dominate the indirect effects, that is $U_{m_{i}}^{i^{\prime}} U_{m_{j}}^{j^{\prime}}>U_{m_{i}}^{j^{\prime}} U_{m_{j}}^{i^{\prime}}$ where $U_{x}^{i^{\prime}}=\frac{\partial U^{i}}{\partial m_{i} \partial x}$. A detailed derivation of the comparative statics is relegated to the Appendix. Making use of the Dixit (1986) stability assumptions we obtain

$$
\begin{aligned}
& \frac{\mathrm{d} m_{i}}{\mathrm{~d} b_{i 0}}=-\frac{1}{\Delta} U_{m_{j}}^{j^{\prime}} U_{b_{i 0}}^{i^{\prime}}<0, \\
& \frac{\mathrm{d} m_{j}}{\mathrm{~d} b_{i 0}}=\frac{1}{\Delta} U_{m_{i}}^{j^{\prime}} U_{b_{i 0}}^{i^{\prime}} \gtreqless 0,
\end{aligned}
$$

with $\Delta=U_{m_{i}}^{i^{\prime}} U_{m_{j}}^{j^{\prime}}-U_{m_{i}}^{j^{\prime}} U_{m_{j}}^{i^{\prime}}>0$ and $U_{b_{i 0}}^{i^{\prime}}=h_{1}^{\prime \prime}(1+r) \gamma^{2} c^{\prime}<0$. The latter inequality means that the incentive to invest in infrastructure declines with higher legacy debt, as the marginal utility of consumption rises when $h_{1}^{\prime \prime}<0$. An increase in legacy debt in $i$ leads unambiguously to a decline in infrastructure investment in $i$, as can be seen in expression (14). Ideally, the additional legacy debt should be distributed across and repaid in both periods to smooth consumption. Yet this cannot be done if the willingness-to-pay condition is binding. The burden from the additional debt falls ceteris paribus on period 1 and raises the marginal utility of consumption in period 1, thus making a transfer of resources from period 2 to period 1 even more desirable. A second best government response to this problem is to reduce investment in public infrastructure in that jurisdiction which by lower spending in period 1 increases the space for public good consumption in that period.

The effect of $i$ 's legacy debt on the infrastructure investment in the other jurisdiction is less clear cut. The sign depends on the cross partial effect, $U_{m_{j}}^{j^{\prime}}$, which captures the change in the net benefit of public infrastructure investment in one jurisdiction if the government in the other jurisdiction invests more (or less). The sign defines also whether the two jurisdictions' levels of infrastructure spending are strategic substitutes or complements. We can derive an unambiguous effect if we assume that the inter-temporal utility function is of the quasi-linear type, that is, $h_{2}^{\prime \prime}=0$. In this case the cross effect $U_{m_{i}}^{j^{\prime}}$ is negative and the overall effect on $m_{j}$ is positive. Infrastructure investments are strategic substitutes ${ }^{16}$ and move in opposite directions when one jurisdiction's legacy debt rises.

The case of diverging trends in infrastructure investment carries implications for the period 2 tax equilibrium. In particular, starting from a symmetric situation (with equal initial debts) and symmetric infrastructure investments, an increase in a jurisdiction's initial debt leads to a lower tax rate for that jurisdiction in period 2, while the opposite holds in the other jurisdiction. The latter can now afford a higher tax because the better relative standing in public infrastructure partially offsets higher taxes. In other words, legacy debt affects fiscal competition when a government is constrained in borrowing.

As in the case with no restriction on public borrowing, higher capital mobility, captured

\footnotetext{
${ }^{16}$ This a standard feature in fiscal competition models (e.g. Hindriks et al., 2008). For a discussion on the role of public inputs in fiscal competition see Matsumoto (1998).
} 
by a decrease in $\nu$, generally has a decreasing effect on equilibrium tax rates. In addition to this direct effect, a binding constraint on public borrowing in period 1 introduces a second impact of capital mobility. By affecting the level of tax rates in period $1, \nu$ changes $U_{b_{i 0}}^{i^{\prime}}$. In particular, $\frac{d U_{b_{i 0}}^{i^{\prime}}}{d \nu}=h_{1}^{\prime \prime \prime}(1+r) \gamma^{3} c^{\prime}$ is positive if and only if $h_{1}^{\prime \prime \prime}>0$. The latter property holds for a range of strictly concave functions, including the logarithmic form used above. Since $U_{b_{i 0}}^{i^{\prime}}<0$, the property implies that a higher degree of capital mobility reinforces the depleting effect of legacy debt on public infrastructure investment and period 2 tax rates. Intuitively, higher capital mobility in period 1 reduces the government's revenue from taxing capital, making it more sensitive to additional burden in period 1 such as initial debt consolidation. In an environment with high capital mobility, governments with high legacy debt levels find it even less attractive to shift resources to the future by investing in public infrastructure. Consequently, they also set even lower tax rates in period 2.

\section{Case IIb: Willingness-to-pay Condition is binding in only one jurisdiction}

The final case involves an asymmetry. One jurisdiction can freely choose $b_{i 1}$ whereas for the other jurisdiction Condition 1 is binding. This could for example be the case if jurisdictions face different levels of $z$. For instance, jurisdictions whose finances depend more on international credit markets can convince potential lenders more easily that they are willing to repay the debt later to keep their access to the credit market. A similar situation can be described for jurisdictions whose economy is more vulnerable to shocks following the default decision.

For the equilibrium analysis, we need not specify exactly where the asymmetry comes from. Let us assume that Condition 1 is binding in jurisdiction $i$, but not in $j$. Then, the Nash equilibrium is characterized by five first order conditions ${ }^{17}$, two for $i$ (w.r.t. $m_{i}$ and $\tau_{i}$ ) and three for $j$ (w.r.t. $m_{j}, \tau_{j}$ and $b_{j 1}$ ). The two first order conditions for the tax rates in period 1 can still be solved separately. Furthermore, the condition for optimal borrowing in jurisdiction $j$ implies that $g_{j 1}=\frac{1}{2 \gamma}$, as in Case I. However, in this case we cannot easily solve the remaining first order conditions. Still, we now expect asymmetric spending on public infrastructure and effects of initial debt level in jurisdiction $i$ affecting its infrastructure investment and thus period 2 equilibrium tax rates.

More formally, we can undertake comparative static analysis with respect to legacy debt levels. Below we show that Case IIb can be treated as a combination of Cases I and IIa. We thus relegate the technical details of this supplementary analysis to the Appendix and only state the main results. First, an increase in legacy debt in jurisdiction $i$ leads to opposite effects on infrastructure investment in the two jurisdictions. Second, the effects of such an increase on period 1 debt and infrastructure investment in the unconstrained jurisdiction go in the same direction: the unconstrained jurisdiction spends more on public infrastructure and borrows more at the same time. Finally, a change in legacy debt in jurisdiction $j$ is

\footnotetext{
${ }^{17}$ After substituting the government budget constraint in period 1 into the objective function, as before.
} 
neutral, as in Case I. The unconstrained jurisdiction can still shift resources across periods as it wishes to. Therefore the marginal cost of increasing public infrastructure spending in period 1 depends only on the cost function $c$, but not on the level of borrowing. The main insight from Case IIa carries over: An increase in legacy debt in a jurisdiction that faces a binding constraint in public borrowing leads to a decrease in period 2 tax rates of this jurisdiction.

We summarize the results from Cases IIa,b as follows:

Proposition 3. Let $2>\gamma \nu>1$. Assume that at least one jurisdiction is constrained in its borrowing decision in period 1 (i.e., Condition 1 is binding) and initial public infrastructure levels are symmetric $\bar{q}_{i}=\bar{q}_{j}$.

a) If Condition 1 is binding in both jurisdictions and the Nash equilibrium in infrastructure spending is stable, an increase in jurisdiction $i$ 's legacy debt $\left(b_{i 0}\right)$ leads to a decline in infrastructure investment $\left(m_{i}\right)$ and also reduces $i$ 's period 2 tax rate $\left(\tau_{i 2}\right)$. Assuming quasi-linear preferences it increases infrastructure spending in $j\left(m_{j}\right)$, and thus a rise in $j$ 's tax in period $2\left(\tau_{j 2}\right)$.

b) If only one jurisdiction is constrained in borrowing, an increase in that jurisdiction's legacy debt affects infrastructure spending and tax rates in period 2. Changes in initial debt of an unconstrained jurisdiction are neutral to the location game in period 2 and leave period 2 tax rates and infrastructure investment unaffected.

c) A decrease in $\nu$ (i.e. firms become more footloose) lowers tax rates in both jurisdictions in both periods. In addition, higher $\nu$ weakly increases the negative effect of legacy debt on the public investment level and period 2 tax rates in a jurisdiction that faces a binding borrowing constraint.

We need to make sure that public good consumption level in period 1 is indeed positive. When Condition 1 is binding, $g_{i 1}>0 \Leftrightarrow \frac{1}{2}\left(\nu-\frac{1}{\gamma}\right)-c+b^{w t p}>(1+r) b_{i 0}$. A sufficiently small initial level of debt is required to ensure the condition is met. This requirement results from the initial debt being an exogenous burden on the public good consumption in period 1. Finally, $2>\gamma \nu>1$ ensures that $\tau_{i 1}^{*}, b_{i 1}^{\text {des }}>0$.

It is interesting to put our main results in the context of the scarce literature on tax competition and public debt. As noted in the introduction, Arcalean (2015) is close to but different from our work. In his model government debt is always repaid. Financial liberalization puts pressure on tax rates which in turn leads to more capital accumulation, which can be taxed and brought forward through higher initial budget deficits. This incentive works because the median voter, who by assumption is a worker with labor income only, redistributes income through capital taxation to herself intratemporally and through debt intertemporally. Our paper can be seen as complementary by emphasizing the role of initial (legacy) debt and focusing on a different mechanism through investment in public infrastructure. Our results can also be related to Jensen \& Toma (1991), who show that period 1 debt affects period 2 capital tax rates even in the absence of default. While the models 
are different in some other aspects, it appears that the linear within-period utility function in our model drives this difference. This assumption is useful for our purposes in order to clearly identify the role of default which we obtain by comparing the results from Case I and Cases II, respectively.

\subsection{Asymmetric Initial Public Infrastructure Levels}

In our analysis above, we have assumed that an inter-jurisdictional difference in the level of legacy debt is the only source of asymmetry in period 1 . We now allow for an additional asymmetry, namely in initial infrastructure $\left(\bar{q}_{i} \neq \bar{q}_{j}\right)$. We discuss how this affects our results, summarizing our main findings below and relegating a more formal derivation to the Appendix. An asymmetric level of initial public infrastructure has several implications. First, ceteris paribus it causes the better endowed and thus generally more attractive jurisdiction to set higher taxes because the resulting loss in private investment projects is smaller than in the jurisdiction with inferior infrastructure. This effect takes place in period 1 , and also in period 2 if public infrastructure does not fully depreciate $(\delta<1)$. Second, the asymmetric equilibria in the tax competition game in each period feed into the inter-temporal fiscal variables. A higher level of public infrastructure attracts more private activity which in turn raises the incentive for additional public infrastructure spending. This relates to the polarization effect described by Cai \& Treisman (2005). More public infrastructure investment also raises the level of desired public borrowing in period $1, b_{i 1}^{\text {des }}$, which increases further because the better endowed jurisdiction shifts part of the benefits from a higher level of period 2 tax revenue to period 1 .

A higher level of existing public infrastructure thus improves a jurisdiction's position in the subsequent fiscal competition game. A particularly interesting case arises when the initial asymmetry is related to legacy debt. To understand the consequences of such a correlation let us suppose that the initial level of public infrastructure is a function of legacy debt, $\bar{q}_{i}=f\left(b_{i 0}\right)$. Intuitively, there are two forms in which such a relation may be observed. For example, Poterba (1995) points out that the possibility of debt financing of public investment spending can make it easier to obtain support for government investment projects as they appear less costly to the public. Thus, if higher legacy debt levels are an indicator of higher public infrastructure spending in the past, the relationship is positive, that is, $f^{\prime}>0$. High legacy debt levels may, however, also result from a structural deficit in the jurisdiction caused by public consumption spending. In this case, the level of existing infrastructure may be negatively related to the observed legacy debt, and therefore $f^{\prime}<0$.

We now show that the sign of the relationship between initial levels of debt and infrastructure is key for understanding asymmetries in public infrastructure.

Proposition 4. Let existing public infrastructure be a continuously differentiable function of legacy debt, $\bar{q}_{i}=f\left(b_{i 0}\right)$, and initial debt be positively (negatively) related to initial public infrastructure, $f^{\prime}>0\left(f^{\prime}<0\right)$. An increase in jurisdiction $i$ 's legacy debt $\left(b_{i 0}\right)$ leads to an 
increase (a decline) in infrastructure investment $\left(m_{i}\right)$ and also increases (reduces) i's period 2 tax rate $\left(\tau_{i 2}\right)$ if

a) Condition 1 is not binding in both jurisdictions (Case I), or

b) Condition 1 is binding in both jurisdictions (Case II), $\delta=1$ and the marginal decrease (increase) in period 1 government revenue resulting from the lower (higher) level of initial public infrastructure is greater than the marginal increase in the repayment burden.

The formal argument is given in the Appendix. Here we discuss the results intuitively. If legacy debt has no effect on inter-temporal redistribution (Case I), only the polarization effect from public infrastructure spending is decisive. This implies in the case of unrestricted public borrowing that the choice of $m_{i}$ is no longer independent of $b_{i 0}$, but indirectly linked to it through $\bar{q}_{i}$. If higher legacy debt is associated with more public investment in the past, then higher $b_{i 0}$ leads to more infrastructure spending in period 1. In contrast, if higher initial debt in period 1 has to be attributed to high consumption spending, then higher $b_{i 0}$ implies a lower level of infrastructure spending in period $1 .{ }^{18}$

Inter-temporal considerations are relevant if public borrowing is restricted (Case II). In addition to the polarization effect, the government's incentive to redistribute between periods is affected. To illustrate this point, assume that high legacy debt indicates a low level of public infrastructure installments in the past. The jurisdiction with a higher initial debt level faces a stronger incentive to redistribute resources to period 1 because the coinciding lower level of existing public infrastructure implies less public revenue in period 1. As a consequence it chooses a lower level of additional infrastructure spending and consequently also taxes less. The opposite is the case if $\bar{q}_{i}$ and $b_{i 0}$ are negatively related.

In general, even in the presence of an additional asymmetry resulting from the relation of $\bar{q}_{i}$ and $b_{i 0}$ it is still true that a higher repayment burden in period 1 incentivizes intertemporal redistribution either via additional borrowing or lower infrastructure spending. The new effect from the additional asymmetry may, however, reinforce or mitigate the incentive since a change in $b_{i 0}$ also changes $\bar{q}_{i}$. An interesting special case arises when public infrastructure fully depreciates $(\delta=1) .{ }^{19}$ As formalized in condition (A.12) in the Appendix, higher $b_{i 0}$ increases public infrastructure spending in period 1 if the marginal increase in government revenue resulting from the coinciding increase in initial public infrastructure is greater than the resulting marginal increase in the repayment burden. This follows the simple intuition that public debt does not become a structural problem as long as governments use the additional funds to generate higher revenues in a later period (e.g. by effectively improving public infrastructure).

\footnotetext{
${ }^{18}$ This result is formalized in condition (A.10) in the Appendix.

${ }^{19}$ This simplifies the exposition as it abstracts from any effect of initial public infrastructure in period 2.
} 


\subsection{Numerical Example}

We complement our analysis with a numerical example that illustrates the working of the model and allows to check the consistency of the solution derived above. We return to the case of symmetric initial infrastructure levels $\left(\bar{q}_{i}=\bar{q}_{j}\right)$ and assume the utility function to be quasi-linear with $h_{1}(x)=\ln (x)$ and $h_{2}(x)=x$, and the investment cost function to be quadratic, $c\left(m_{i}\right)=m_{i}^{2}$. We set $\rho=1.4, \nu=1.4, \gamma=1.3, \delta=1$ and $z=0.25$. Furthermore, we let $r=0.01$ such that $\beta=0.99$ and assume $\bar{q}_{i}=\bar{q}_{j}$. The upper limit for public borrowing in period 1 is then $b^{w t p}=0.19$. We solve the model using a simple iterative algorithm. Solutions for the key variables are displayed in Table 1. The full set of variables is presented in the Appendix.

Table 1: Numerical Solution

\begin{tabular}{lcccccc}
\hline & \multicolumn{2}{c}{ Case I } & \multicolumn{2}{c}{ Case IIa } & \multicolumn{2}{c}{ Case IIb } \\
Jurisdiction & 1 & 2 & 1 & 2 & 1 & 2 \\
\hline$b_{i 0}$ & 0.06 & 0.05 & 0.20 & 0.10 & 0.20 & 0.05 \\
$b_{i 1}^{\text {des }}$ & 0.18 & 0.17 & 0.31 & 0.22 & 0.31 & 0.17 \\
$m_{i}^{*}$ & 0.23 & 0.23 & 0.19 & 0.22 & 0.19 & 0.23 \\
$\tau_{i 2}^{*}$ & 0.63 & 0.63 & 0.62 & 0.64 & 0.61 & 0.65 \\
\hline
\end{tabular}

In the first two columns of Table 1 we present a solution for Case I. Initial debt levels are very low such that the desired borrowing level in period 1 is below the willingness-to-pay threshold and Condition 1 is not binding. As expected, public infrastructure investment and period 2 tax rates are identical across jurisdictions. We proceed to Case IIa in the second column where initial debt is set higher to generate a situation with a binding borrowing constraint. Now we have an asymmetric solution for public investment and period 2 tax rates: The jurisdiction with the higher level of legacy debt (jurisdiction 1) invests less and sets lower taxes. Again, this follows the theoretical analysis from above. Finally, we set initial debt levels such that we can demonstrate the outcome for Case IIb. In our example, the initial debt level is high in jurisdiction 1, such that Condition 1 is binding there. Jurisdiction 2 has a lower level of legacy debt and does not face a binding constraint on borrowing in the first period. Consequently, the constrained jurisdiction displays a lower level of public investment and has a lower tax rate. ${ }^{20}$

\footnotetext{
${ }^{20}$ In the Appendix, we provide an additional solution in column Case IIb' where we increase legacy debt in jurisdiction 2 to demonstrate that this has no effect on equilibrium tax rates and investment since Condition 1 is not binding for jurisdiction 2 .
} 


\section{Conclusion}

In this paper we have used a two-jurisdiction, two-period model to analyze a fiscal competition game with asymmetric initial public debt levels. We first show that, with unlimited government borrowing, the level of legacy public debt does not affect the fiscal competition game. Governments merely shift the repayment burden to future generations by increasing additional borrowing one by one. We then allow for government default which endogenously imposes an upper bound on public debt. This restricts inter-temporal redistribution of governments and provides an important theoretical link between legacy debt and fiscal competition.

We show that in the presence of restricted public borrowing the government's decision on long-term infrastructure investment is shaped by its desire to optimally allocate resources between periods. A higher level of legacy debt causes the government to decrease public investment in the first period, making the jurisdiction a less attractive location for private investment in the following period. Governments partly compensate this disadvantage by setting lower tax rates in the second period. In our two-jurisdiction model, the more indebted jurisdiction (in terms of legacy debt), therefore, invests less and sets a lower tax on capital. This mechanism is weakly stronger, the higher is the level of capital mobility. Capital mobility, therefore, leads not only to downward pressure on tax rates, as is well known from the literature, but tends to reinforce the effect of initial debt.

Besides developing a theoretical framework for the analysis of fiscal competition in the presence of government debt levels, the theoretical results might be helpful in providing clearer predictions for empirical analysis of fiscal competition. In particular, our findings suggest a link between the heterogeneity of debt levels and the variation in taxes on mobile tax bases. In the sense of Cai \& Treisman (2005), debt levels constitute a potential source of initial asymmetry that may induce an asymmetric equilibrium in the fiscal competition game. In particular, larger differences in debt levels across jurisdictions are expected to lead to tax divergence which is reinforced by greater capital mobility.

This result also provides important insights into current policy debates. For example, in Germany the federal states (Länder) have little tax autonomy. Some policy makers and many academics strongly support more tax autonomy for states (income tax, business tax). Given that states differ widely in existing debt levels, it is not clear whether and how existing debt would influence the competitiveness in a subsequent fiscal competition game. Our model suggests that default on government debt might play a crucial role. If states gain not only more tax autonomy, but also obtain more responsibility for ultimately balancing their budget, initial debt levels matter.

On the other hand, inter-jurisdictional harmonization efforts in the area of business taxation may prove difficult as long as there are great differences in public debt levels. The problem is that jurisdictions with a high debt repayment burden may have very different fiscal policy strategies than governments with a low level of consolidation requirement. 
We believe that our work contributes to clarifying the effect of government debt for fiscal competition. While we consider our mechanism to be relevant, it is by no means the only channel through which legacy debt may matter. In interesting complementary work, Arcalean (2015) considers the link between tax competition and endogenous debt levels, both as functions of the degree of financial liberalization. In contrast to his work, we emphasize the role of default which appears to be relevant in many situations. Following our approach, future work could consider the effects of bailouts when default occurs, or the effect of fiscal rules that are currently in widespread. Both of these extensions would add more realism to the analysis.

Throughout our analysis we have focused on the positive aspects of changes in capital mobility and legacy debt. Normative issues are clearly relevant. However, the current model is probably not ideal for welfare analysis. For example, the total number of firms is fixed and thus independent of tax rates and public infrastructure. This appears quite special, but the setup turns out to be tractable this way. Future works should also address the welfare implications of fiscal competition when government debt matters.

\section{References}

Acharya, Viral V, \& Rajan, Raghuram G. 2013. Sovereign debt, government myopia, and the financial sector. Review of Financial Studies, 26(6), 1526-1560.

Arcalean, Calin. 2015. International tax competition and the deficit bias. CESifo Working Paper No. 562\%.

Barro, Robert J. 1979. On the determination of the public debt. The Journal of Political Economy, 87(5), 940-971.

Battaglini, Marco, \& Coate, Stephen. 2008. A dynamic theory of public Spending, taxation, and debt. American Economic Review, 98(1), 201-36.

Borck, Rainald, Fossen, Frank M, Freier, Ronny, \& Martin, Thorsten. 2015. Race to the debt trap? Spatial econometric evidence on debt in German municipalities. Regional Science and Urban Economics, 53, 20-37.

Brueckner, Jan K. 1998. Testing for strategic interaction among local governments: The case of growth controls. Journal of Urban Economics, 44(3), 438-467.

Bucovetsky, Sam. 2005. Public input competition. Journal of Public Economics, 89(9), $1763-1787$.

Cai, Hongbin, \& Treisman, Daniel. 2005. Does competition for capital discipline governments? Decentralization, globalization, and public policy. American Economic Review, 95(3), 817-830. 
Dixit, Avinash. 1986. Comparative statics for oligopoly. International Economic Review, 27(1), 107-122.

Hauptmeier, Sebastian, Mittermaier, Ferdinand, \& Rincke, Johannes. 2012. Fiscal competition over taxes and public inputs. Regional Science and Urban Economics, 42(3), 407-419.

Hindriks, Jean, Peralta, Susana, \& Weber, Shlomo. 2008. Competing in taxes and Investment under fiscal equalization. Journal of Public Economics, 92(12), 2392-2402.

Hotelling, Harold. 1929. Stability in competition. The Economic Journal, 39(153), 41-57.

Jensen, Richard, \& Toma, Eugenia Froedge. 1991. Debt in a model of tax competition. Regional Science and Urban Economics, 21(3), 371-392.

Keen, Michael, \& Konrad, Kai A. 2013. The theory of international tax competition and coordination. Pages 257-328 of: Auerbach, Alan, Chetty, Raj, Feldstein, Martin, \& Saez, Emanuel (eds), Handbook of Public Economics, Volume 5. Amsterdam \& Oxford, Elsevier.

Matsumoto, Mutsumi. 1998. A note on tax competition and public input provision. Regional Science and Urban Economics, 28(4), 465-473.

Noiset, Luc. 1995. Pigou, tiebout, property taxation, and the underprovision of local public goods: comment. Journal of Urban Economics, 38(3), 312-316.

Petchey, Jeffrey D, \& Shapiro, Perry. 2009. Equilibrium in fiscal competition games from the point of view of the dual. Regional Science and Urban Economics, 39(1), 97-108.

Poterba, James M. 1995. Capital budgets, borrowing rules, and state capital spending. Journal of Public Economics, 56(2), 165-187.

Wilson, John Douglas. 1986. A theory of interregional tax competition. Journal of Urban Economics, 19(3), 296-315.

Wilson, John Douglas. 2005. Welfare-improving competition for mobile capital. Journal of Urban Economics, 57(1), 1-18.

Winner, Hannes. 2005. Has tax competition emerged in OECD countries? Evidence from panel data. International Tax and Public Finance, 12(5), 667-687.

Zodrow, George R, \& Mieszkowski, Peter. 1986. Pigou, tiebout, property taxation, and the underprovision of local public goods. Journal of Urban Economics, 19(3), 356-370. 


\section{Appendix}

\section{Second Order Conditions for Case I}

The Hessian for the system of first order conditions (9) to (11) is given by

$$
H=\left(\begin{array}{ccc}
U_{m_{i}}^{m_{i}} & U_{m_{i}}^{\tau_{i 1}} & U_{m_{i}}^{b_{i 1}} \\
U_{\tau_{i 1}}^{m_{i}} & U_{\tau_{i 1}}^{\tau_{i 1}} & U_{\tau_{i 1}}^{b_{i 1}} \\
U_{b_{i 1}}^{m_{i}} & U_{b_{i 1}}^{\tau_{i 1}} & U_{b_{i 1}}^{b_{i 1}}
\end{array}\right)=\left(\begin{array}{ccc}
U_{m_{i}}^{m_{i}} & 0 & U_{m_{i}}^{b_{i 1}} \\
0 & U_{\tau_{i 1}}^{\tau_{i 1}} & 0 \\
U_{b_{i 1}}^{m_{i}} & 0 & U_{b_{i 1}}^{b_{i 1}}
\end{array}\right)
$$

where $U_{y}^{x_{i}}=\frac{\partial^{2} U^{i}}{\partial x_{i} \partial y}$. In the second term we have inserted the first order condition for taxes (9) to verify $U_{\tau_{i 1}}^{m_{i}}=-h_{1}^{\prime \prime} \frac{\partial\left(N_{i 1}\left(1+\gamma \tau_{i 1}\right)\right)}{\partial \tau_{i 1}} \gamma c^{\prime}=0$ and $U_{\tau_{i 1}}^{b_{i 1}}=\gamma h_{1}^{\prime \prime} \frac{\partial\left(N_{i 1}\left(1+\gamma \tau_{i 1}\right)\right)}{\partial \tau_{i 1}}=0$. For (9)-(11) to yield a maximum, $H$ must be negative definite. This is the case if and only if

$$
\begin{aligned}
& U_{m_{i}}^{m_{i}}=-h_{1}^{\prime \prime}\left(\gamma c^{\prime}\right)^{2}-h_{1}^{\prime} \gamma c^{\prime \prime}+\beta h_{2}^{\prime \prime}\left(\frac{\partial N_{i 2}\left(1+\gamma \tau_{i 2}\right)}{\partial m_{i}}\right)^{2}+\beta \gamma h_{2}^{\prime} \frac{\partial N_{i 2}}{\partial m_{i}} \frac{\partial \tau_{i 2}}{\partial m_{i}}<0 \\
& U_{m_{i}}^{m_{i}} U_{\tau_{i 1}}^{\tau_{i 1}}>0 \\
& U_{\tau_{i 1}}^{\tau_{i 1}}\left(U_{m_{i}}^{m_{i}} U_{b_{i 1}}^{b_{i 1}}-\left(U_{m_{i}}^{b_{i 1}}\right)^{2}\right)<0 .
\end{aligned}
$$

Condition (A.1) is fulfilled for any sufficiently convex public investment cost function $c$, i.e. large enough $c^{\prime \prime}$. Since $U_{\tau_{i 1}}^{\tau_{i 1}}=-h_{1}^{\prime} \frac{\gamma}{\nu}<0$, (A.2) must hold whenever (A.1) holds. Then, for (A.3) to hold in conjunction with (A.1), we must have $U_{b_{i 1}}^{b_{i 1}}<0$ and a sufficiently convex $c$ such that $U_{m_{i}}^{m_{i}} U_{b_{i 1}}^{b_{i 1}}>\left(U_{m_{i}}^{b_{i 1}}\right)^{2}$ where $U_{m_{i}}^{b_{i 1}}=-h_{1}^{\prime \prime} \gamma^{2} c^{\prime}-\gamma h_{2}^{\prime \prime}\left(\frac{\partial N_{i 2}\left(1+\gamma \tau_{i 2}\right)}{\partial m_{i}}\right)$. Note that $U_{b_{i 1}}^{b_{i 1}}<0 \Longleftrightarrow \beta>\frac{h_{2}^{\prime \prime}}{h_{1}^{\prime \prime}}$ which is always true in the quasi-linear case. More generally, $h_{1}$ needs to be sufficiently more concave than $h_{2}$ in order to make it optimal to distribute resources between the two periods rather than shifting all resources into period 2 .

\section{Comparative Statics for Case IIa}

Taking the total differential of the first order conditions we arrive at the following system of equations

$$
\left(\begin{array}{cc}
U_{m_{i}}^{i^{\prime}} & U_{m_{j}}^{i^{\prime}} \\
U_{m_{i}}^{j^{\prime}} & U_{m_{j}}^{j^{\prime}}
\end{array}\right)\left(\begin{array}{c}
\mathrm{d} m_{i} \\
\mathrm{~d} m_{j}
\end{array}\right)+\left(\begin{array}{c}
U_{b_{i 0}}^{i^{\prime}} \\
0
\end{array}\right) \mathrm{d} D_{i o}=0
$$

which can be rearranged to yield equations (14) and (15). Since $U_{b_{i 0}}^{i^{\prime}}<0$, the Dixit (1986) stability conditions,

$$
U_{m_{i}}^{i^{\prime}}<0, U_{m_{j}}^{j^{\prime}}<0, U_{m_{i}}^{i^{\prime}} U_{m_{j}}^{j^{\prime}}>U_{m_{i}}^{j^{\prime}} U_{m_{j}}^{i^{\prime}}
$$


imply $\frac{\mathrm{d} m_{i}}{\mathrm{~d} b_{i 0}}<0$. If $h_{2}^{\prime \prime}=0$ such that $U^{i}$ is quasi-linear, we can show that $\frac{\mathrm{d} m_{j}}{\mathrm{~d} b_{i 0}}<0$ by verifying that in this case

$$
U_{m_{i}}^{j^{\prime}}=-\beta h_{2}^{\prime \prime}\left(\frac{\rho}{6 \nu}+\frac{\gamma \rho}{3}\left(\frac{1}{2 \nu} \tau_{i 2}+N_{i 2}\right)\right)^{2}-\frac{\gamma \rho^{2}}{9 \nu} \beta h_{2}^{\prime}=-\frac{\gamma \rho^{2}}{9 \nu} \beta h_{2}^{\prime}<0
$$

\section{Comparative Statics for Case IIb}

We assume that Condition 1 is binding in $i$ but not in $j$. Then the system of first order conditions is given by

$$
\begin{aligned}
U^{\tau_{i 1} 1} & :=\frac{\partial U^{i}}{\partial \tau_{i 1}}=h_{1}^{\prime} \frac{\partial\left(N_{i 1}\left(1+\gamma \tau_{i 1}\right)\right)}{\partial \tau_{i 1}}=0 \\
U^{\tau_{j 1} 1} & :=\frac{\partial U^{j}}{\partial \tau_{j 1}}=h_{1}^{\prime} \frac{\partial\left(N_{j 1}\left(1+\gamma \tau_{j 1}\right)\right)}{\partial \tau_{j 1}}=0 \\
U^{m_{i}} & :=\frac{\partial U^{i}}{\partial m_{i 1}}=-h_{1}^{\prime} \gamma c^{\prime}+\beta h_{2}^{\prime} \frac{\partial\left(N_{i 2}\left(1+\gamma \tau_{i 2}\right)\right)}{\partial m_{i}}=0 \\
U^{m_{j}} & :=\frac{\partial U^{j}}{\partial m_{j 1}}=-h_{1}^{\prime} \gamma c^{\prime}+\beta h_{2}^{\prime} \frac{\partial\left(N_{j 2}\left(1+\gamma \tau_{j 2}\right)\right)}{\partial m_{j}}=0 \\
U^{b_{j 1}} & :=\frac{\partial U^{j}}{\partial b_{j 1}}=\gamma h_{1}^{\prime}-\beta \gamma(1+r) h_{2}^{\prime}=h_{1}^{\prime}-h_{2}^{\prime}=0,
\end{aligned}
$$

The requirements for the second order conditions in each jurisdiction are identical to those derived for Case I. The first order conditions for taxes, (A.4) and (A.5), yield again (12). Substituting (A.8) into (A.7), we can rewrite the first order condition for public investment in $j$ to $\tilde{U}_{m_{j}}^{j^{\prime}}=-\gamma c^{\prime}+\beta \frac{\partial\left(N_{j 2}\left(1+\gamma \tau_{j 2}\right)\right)}{\partial m_{j}}=0$. The Dixit (1986) stability conditions are then written as

$$
U_{m_{i}}^{i^{\prime}}<0, \tilde{U}_{m_{j}}^{j^{\prime}}<0, U_{i, m_{i}} \tilde{U}_{m_{j}}^{j^{\prime}}>\tilde{U}_{m_{i}}^{j^{\prime}} U_{m_{j}}^{i^{\prime}}
$$

Taking the total differential of the first order conditions with respect to $b_{i 0}$ we arrive at the following system of equations

$$
\left(\begin{array}{cc}
U_{m_{i}}^{i^{\prime}} & U_{m_{j}}^{i^{\prime}} \\
\tilde{U}_{m_{i}}^{j^{\prime}} & \tilde{U}_{m_{j}}^{j^{\prime}}
\end{array}\right)\left(\begin{array}{c}
\mathrm{d} m_{i} \\
\mathrm{~d} m_{j}
\end{array}\right)+\left(\begin{array}{c}
U_{b_{i 0}}^{i^{\prime}} \\
0
\end{array}\right) \mathrm{d} b_{i 0}=0
$$

which can be rearranged to yield

$$
\begin{aligned}
& \frac{\mathrm{d} m_{i}}{\mathrm{~d} b_{i 0}}=-\frac{1}{\tilde{\Delta}} \tilde{U}_{m_{j}}^{j^{\prime}} U_{b_{i 0}}^{i^{\prime}}<0 \\
& \frac{\mathrm{d} m_{j}}{\mathrm{~d} b_{i 0}}=\frac{1}{\tilde{\Delta}} \tilde{U}_{m_{i}}^{j^{\prime}} U_{b_{i 0}}^{i^{\prime}}>0
\end{aligned}
$$


with $\tilde{\Delta}=U_{i, m_{i}} \tilde{U}_{m_{j}}^{j^{\prime}}-\tilde{U}_{m_{i}}^{j^{\prime}} U_{m_{j}}^{i^{\prime}}>0$. The second effect can be clearly signed because $\tilde{U}_{m_{i}}^{j^{\prime}}=$ $\beta \frac{\partial\left(N_{j 2}\left(1+\gamma \tau_{j 2}\right)\right)}{\partial m_{j} \partial m_{i}}=-\frac{\gamma \rho^{2}}{9 \nu}<0$. Taking the total differential of the first order conditions with respect to $b_{j 0}$ we obtain

$$
\left(\begin{array}{cc}
U_{m_{i}}^{i^{\prime}} & U_{m_{j}}^{i^{\prime}} \\
\tilde{U}_{m_{i}}^{j^{\prime}} & \tilde{U}_{m_{j}}^{j^{\prime}}
\end{array}\right)\left(\begin{array}{c}
\mathrm{d} m_{i} \\
\mathrm{~d} m_{j}
\end{array}\right)+\left(\begin{array}{c}
0 \\
\tilde{U}_{b_{j 0}}^{j^{\prime}}
\end{array}\right) \mathrm{d} b_{j 0}=0
$$

which we rearrange to

$$
\begin{aligned}
& \frac{\mathrm{d} m_{i}}{\mathrm{~d} b_{i 0}}=\frac{1}{\tilde{\Delta}} \tilde{U}_{m_{j}}^{j^{\prime}} \tilde{U}_{b_{j 0}}^{j^{\prime}}=0 \\
& \frac{\mathrm{d} m_{j}}{\mathrm{~d} b_{i 0}}=-\frac{1}{\tilde{\Delta}} \tilde{U}_{m_{i}}^{j^{\prime}} \tilde{U}_{b_{j 0}}^{j^{\prime}}=0
\end{aligned}
$$

where the equality follows from $\tilde{U}_{b_{j 0}}^{j^{\prime}}=0$.

\section{Asymmetries in Initial Public Infrastructure}

Our analysis proceeds in two steps. First we consider the situation where initial debt and initial infrastructure are not related. After that we consider the relationship between the two variables, both under unrestricted and restricted borrowing.

Exogenous $\bar{q}_{i} \quad$ For Case I, the first order conditions are given by (9), (10) and (11). (9) can be solved to yield $\tau_{i 1}^{*}=\nu-\frac{1}{\gamma}+\frac{\rho \triangle \bar{q}_{i}}{3}$ and, assuming a symmetric equilibrium for public infrastructure spending, (10) reduces to $c^{\prime}\left(m_{i}^{*}\right)=\frac{\beta \rho}{3}\left(1+\frac{\rho}{3 \nu} \triangle \bar{q}_{i}(1-\delta)\right)$ which is independent of $b_{i 0} . b_{i 1}^{\text {des }}$ is derived by substituting these results into (11) and solving for $b_{i 1}$. For example, in the case of log-linear preferences, this yields $b_{i 1}^{\text {des }}=\frac{1}{\gamma}-\frac{\nu}{2}+\frac{\rho \triangle \bar{q}_{i}}{3}\left(1+\frac{\rho \triangle \bar{q}_{i}}{6 \nu}\right)+$ $c+(1+r) b_{i 0}$. For Cases IIa and IIb, the qualitative results of the comparative statics are unaffected by letting $\bar{q}_{i} \neq \bar{q}_{j}$ as long as we abstract from extreme cases of $\triangle \bar{q}_{i}$ where private investment is concentrated in one jurisdiction. This result is obtained because the signs of the second derivatives of $\frac{\partial \tilde{U}_{i}}{\partial m_{i}}$ with respect to $m_{j}, m_{i}, b_{i 0}$ and $b_{j 0}$ are not affected by $\triangle \bar{q}_{i}$.

Linking $\bar{q}_{i}$ and $b_{i 0}$ (Unrestricted Borrowing) Let $\bar{q}_{i}=\bar{q}_{i}\left(b_{i 0}\right)$. (13) must then be modified and reads

$$
c^{\prime}\left(m_{i}\right)=\frac{\beta \rho}{3}\left(1+\frac{\rho}{3 \nu} \triangle m_{i}+\frac{\rho}{3 \nu} \triangle \bar{q}_{i}(1-\delta)\right) .
$$

Taking the total differential of (A.9) with respect to $m_{i}$ and $b_{i 0}$ we obtain

$$
\frac{d m_{i}}{d b_{i 0}}=\frac{\beta \rho^{2}(1-\delta)}{9 \nu c^{\prime \prime}\left(m_{i}\right)-\beta \rho^{2}} \frac{\partial \bar{q}_{i}}{\partial b_{i 0}}
$$


Assuming that second order conditions are met, we know that $\frac{\beta \rho^{2}(1-\delta)}{9 \nu c^{\prime \prime}\left(m_{i}\right)-\beta \rho^{2}}>0$ holds, and thus

$$
\frac{d m_{i}}{d b_{i 0}} \lesseqgtr 0 \Longleftrightarrow \frac{\partial \bar{q}_{i}}{\partial b_{i 0}} \lesseqgtr 0
$$

Linking $\bar{q}_{i}$ and $b_{i 0}$ (Restricted Borrowing) Let $\bar{q}_{i}=\bar{q}_{i}\left(b_{i 0}\right)$ and differentiate (A.6) w.r.t $b_{i 0}$ to obtain

$$
\begin{aligned}
U_{b_{i 0}}^{i^{\prime}}= & h_{1}^{\prime \prime} \gamma c^{\prime} \gamma(1+r)-h_{1}^{\prime \prime} \gamma c^{\prime}\left(1+\gamma \tau_{i 1}\right) \frac{\partial N_{i 1}}{\partial \bar{q}_{i}} \bar{q}_{i}^{\prime} \\
& +\beta\left(h_{2}^{\prime \prime} \frac{\partial\left(N_{i 2}\left(1+\gamma \tau_{i 2}\right)\right)}{\partial \bar{q}_{i}} \frac{\partial\left(N_{i 2}\left(1+\gamma \tau_{i 2}\right)\right)}{\partial m_{i}}+h_{2}^{\prime} \frac{\partial\left(N_{i 2}\left(1+\gamma \tau_{i 2}\right)\right)}{\partial m_{i} \partial \bar{q}_{i}}\right) \bar{q}_{i}^{\prime}
\end{aligned}
$$

which, using (2) and the results from Proposition 1, can be rewritten to yield

$$
\begin{gathered}
U_{b_{i 0}}^{i^{\prime}}=h_{1}^{\prime \prime} \gamma c^{\prime} \gamma(1+r)+\left(\eta^{b}-\eta^{c}\right) \bar{q}_{i}^{\prime} \lessgtr 0, \\
\eta^{c}=h_{1}^{\prime \prime} \gamma c^{\prime}\left(1+\gamma \tau_{i 1}\right) \frac{\rho}{2 \nu}, \eta^{b}=\beta(1-\delta)\left(h_{2}^{\prime \prime}\left(\frac{\partial\left(N_{i 2}\left(1+\gamma \tau_{i 2}\right)\right)}{\partial m_{i}}\right)^{2}+h_{2}^{\prime} \frac{\gamma \rho^{2}}{9 \nu}\right) .
\end{gathered}
$$

The first term in (A.11) captures the effect of $b_{i 0}$ on the marginal utility of public infrastructure investment $\left(U^{i^{\prime}}\right)$ that results from its impact on the incentives for inter-temporal redistribution as described in Proposition 3. The second term $\left(\eta^{c}+\eta^{b}\right) \bar{q}_{i}^{\prime}$ represents the change in $U^{i^{\prime}}$ that is due to the variation in the cost of public investment $\eta^{c}$ and the present value of its benefit $\eta^{b}$, which is caused by a change in $\bar{q}_{i}=\bar{q}_{i}\left(b_{i 0}\right)$. If the first term dominates in magnitude, $U_{b_{i 0}}^{i^{\prime}}<0$, and we obtain the same qualitative results derived in previous sections above. To obtain further insights with regard to the second term, let us assume that $\eta^{b}-\eta^{c}>0$ such that more initial public infrastructure raises the marginal utility of public investment. In our simple model the case $\eta^{b}-\eta^{c}>0$ may arise when public infrastructure depreciates fully between periods $(\delta=1)$. In this case, we abstract from the effect of $\bar{q}_{i}$ on the benefits of public investment $\left(\eta^{b}=0\right)$ and focus on its strictly negative impact on the related cost $\left(\eta^{c}<0\right) .^{21}$

With $\eta^{b}-\eta^{c}>0, \bar{q}_{i}^{\prime}<0 \Longrightarrow U_{b_{i 0}}^{i^{\prime}}<0$. On the contrary, if $\bar{q}_{i}^{\prime}>0$, the effect of initial public debt may be reversed. In the particular case where $\delta=1$

$$
U_{b_{i 0}}^{i^{\prime}} \lesseqgtr 0 \Longleftrightarrow\left(1+\gamma \tau_{i 1}\right) \frac{\rho}{2 \nu} \bar{q}_{i}^{\prime} \lesseqgtr \gamma(1+r)
$$

For more legacy debt to increase the marginal utility of public investment, the marginal increase in government revenue resulting from the coinciding increase in initial public infrastructure must be greater than the resulting marginal increase in the repayment burden.

\footnotetext{
${ }^{21}$ This inequality follows from the concavity of the sub-utility functions.
} 


\section{Numerical Example}

Table A.1: Numerical Solution, Full Set of Variables

\begin{tabular}{llccccccccc}
\hline & & \multicolumn{2}{c}{ Case I } & \multicolumn{2}{c}{ Case IIa } & \multicolumn{2}{c}{ Case IIb } & \multicolumn{2}{c}{ Case IIb' } \\
& Jurisdiction & 1 & 2 & 1 & 2 & 1 & 2 & 1 & 2 \\
\hline \multirow{2}{*}{ Debt } & $b_{i 0}$ & 0.06 & 0.05 & 0.20 & 0.10 & 0.20 & 0.05 & 0.20 & 0.06 \\
& $b_{i 1}^{\text {des }}$ & 0.18 & 0.17 & 0.31 & 0.22 & 0.31 & 0.17 & 0.31 & 0.18 \\
& $b^{\text {wtp }}$ & 0.19 & 0.19 & 0.19 & 0.19 & 0.19 & 0.19 & 0.19 & 0.19 \\
\hline \multirow{2}{*}{ Period 1 } & $b_{i 1}^{*}$ & 0.18 & 0.17 & 0.19 & 0.19 & 0.19 & 0.17 & 0.19 & 0.18 \\
& $m_{i 1}^{*}$ & 0.23 & 0.23 & 0.19 & 0.23 & 0.19 & 0.23 & 0.19 & 0.23 \\
& $N_{i 1}^{*}$ & 0.63 & 0.63 & 0.63 & 0.63 & 0.63 & 0.63 & 0.63 & 0.63 \\
& $g_{i 1}^{*}$ & 0.50 & 0.50 & 0.50 & 0.50 & 0.50 & 0.50 & 0.50 & 0.50 \\
& $\tau_{i 2}^{*}$ & 0.38 & 0.38 & 0.27 & 0.35 & 0.27 & 0.38 & 0.27 & 0.38 \\
\hline & $N_{i 2}^{*}$ & 0.63 & 0.63 & 0.62 & 0.64 & 0.61 & 0.65 & 0.61 & 0.65 \\
& $g_{i 2}^{*}$ & 0.50 & 0.50 & 0.49 & 0.51 & 0.49 & 0.51 & 0.49 & 0.51 \\
\hline \multirow{2}{*}{ Period 2} & 0.13 & 0.14 & 0.11 & 0.13 & 0.11 & 0.15 & 0.11 & 0.15 \\
\hline
\end{tabular}

